\title{
Water-Gas Shift Kinetics Over FeCr-based Catalyst: \\ Effect of Hydrogen sulphide
}

\author{
J. Boon \\ H.A.J. van Dijk \\ O. Pirgon-Galin \\ W.G. Haije \\ R.W. van den Brink
}

Published in Catal Lett (2009) 131:406-412 



\title{
Water-Gas Shift Kinetics Over FeCr-based Catalyst: Effect of Hydrogen Sulphide
}

\author{
Jurriaan Boon · Eric van Dijk • Özlem Pirgon-Galin • \\ Wim Haije $\cdot$ Ruud van den Brink
}

Received: 8 June 2009/ Accepted: 7 July 2009/Published online: 16 July 2009

(C) Springer Science+Business Media, LLC 2009

\begin{abstract}
Kinetics of the water-gas shift reaction over a FeCr-based catalyst is measured with high and low extremes for $\mathrm{CO}_{2}$ and $\mathrm{H}_{2}$ content and containing 11-35 ppmv of $\mathrm{H}_{2} \mathrm{~S}$, relevant for separation-enhanced water-gas shift in IGCC. Kinetics is well described by a power rate law. $\mathrm{H}_{2} \mathrm{~S}$ negatively affects the reaction rate. Comparison with literature shows a more elaborate kinetic model is better suited to fully capture kinetics from sulphur-free to high-sulphur.
\end{abstract}

Keywords Water-gas shift · Hydrogen sulphide ·

Reaction kinetics · Iron oxide/chromia - IGCC .

Pre-combustion decarbonisation

\section{Introduction}

Growing concerns about anthropogenic greenhouse gas emissions have lead to an increased attention for carbon dioxide capture and storage (CCS) worldwide. CCS can be efficiently applied in coal-fuelled integrated gasification combined cycle (IGCC) power plants as pre-combustion technique [1-3]. In pre-combustion $\mathrm{CO}_{2}$ capture, coal is initially gasified to syngas: mainly $\mathrm{H}_{2}$ and $\mathrm{CO}$. Water-gas shift (WGS) is then applied to increase both the $\mathrm{CO}_{2}$ and $\mathrm{H}_{2}$ contents of the syngas:

$\mathrm{CO}+\mathrm{H}_{2} \mathrm{O} \leftrightarrow \mathrm{CO}_{2}+\mathrm{H}_{2} \Delta \mathrm{H}^{298 \mathrm{~K}}=-41.1 \mathrm{~kJ} / \mathrm{mol}$

J. Boon $(\bowtie) \cdot$ E. van Dijk · Ö. Pirgon-Galin · W. Haije ·

R. van den Brink

Hydrogen and Clean Fossil Fuels, Energy Research Centre

of The Netherlands, P.O. Box 1, NL1755ZG Petten,

The Netherlands

e-mail: boon@ecn.nl
The WGS section is typically operated between 300 and $500{ }^{\circ} \mathrm{C}$. The increased $\mathrm{CO}_{2}$ content facilitates $\mathrm{CO}_{2}$ capture and allows for a high carbon capture ratio. Separation of $\mathrm{CO}_{2}$ from the mixture yields $\mathrm{H}_{2}$ that can be used for power generation without $\mathrm{CO}_{2}$ emissions. WGS and $\mathrm{CO}_{2}$ capture can be integrated at elevated temperatures for increased efficiency in a separation-enhanced WGS (SEWGS) reactor, i.e. with selective membranes [4-8] or in presence of a selective $\mathrm{CO}_{2}$ sorbent [9, 10]. In the SEWGS process either $\mathrm{H}_{2}$ or $\mathrm{CO}_{2}$ is removed in situ, thereby enhancing the conversion that would be thermodynamically limited otherwise. An IGCC power plant with integrated WGS and pre-combustion $\mathrm{CO}_{2}$ capture is schematically depicted in Fig. 1. In an IGCC plant, the syngas is desulphurised to a level of 20 ppmv of $\mathrm{H}_{2} \mathrm{~S}$, dictated by corrosion and fouling control in downstream equipment [11, 12]. Desulphurisation is placed upstream of the SEWGS section to prevent $\mathrm{H}_{2} \mathrm{~S}$ from poisoning the membrane as well as to avoid co-capture of $\mathrm{H}_{2} \mathrm{~S}$ with $\mathrm{CO}_{2}[8,13]$, resulting in sweet shift rather than sour shift. For sweet shift, FeCr-based catalysts are used industrially [14, 15]. In separation-enhanced reactors, selective removal of one of the reaction products affects the gas composition in the catalyst bed. Nevertheless, several examples of successful application of FeCr-based catalyst in membrane-enhanced WGS [7, 16, 17] and sorption-enhanced WGS [10] can be found in literature.

$\mathrm{FeCr}$ has been used to catalyse WGS since 1912 and many researchers have since studied its activity, stability, and kinetics [14, 15]. For a narrow range of conditions, literature suggests that the observed reaction kinetics for either clean, sweet, or sour syngas can be described with sufficient accuracy using a power rate law expression $[14,15,18]$ : 


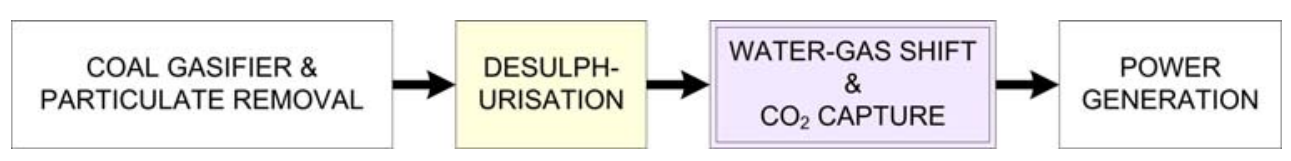

Fig. 1 Schematic of IGCC with pre-combustion $\mathrm{CO}_{2}$ capture: integrated WGS and high-temperature $\mathrm{CO}_{2}$ capture, preceded by desulphurisation

$R=k_{\infty} \exp \left(-E_{\mathrm{a}} / R T\right) p_{\mathrm{CO}}^{n_{\mathrm{CO}}} p_{\mathrm{H}_{2} \mathrm{O}}^{n_{\mathrm{H}_{2} \mathrm{O}}} p_{\mathrm{CO}_{2}}^{n_{\mathrm{CO}_{2}}} p_{\mathrm{H}_{2}}^{n_{\mathrm{H}_{2}}} p_{\mathrm{H}_{2} \mathrm{~S}}^{n_{\mathrm{H}_{2} \mathrm{~S}}}\left(1-\beta_{\mathrm{WGS}}\right)$

$\beta_{\mathrm{WGS}}=\frac{p_{\mathrm{CO}_{2}} p_{\mathrm{H}_{2}}}{K_{\mathrm{eq}, \mathrm{WGS}} p_{\mathrm{CO}} p_{\mathrm{H}_{2} \mathrm{O}}}$

In sweet and sour WGS, the presence of $\mathrm{H}_{2} \mathrm{~S}$ in the feed first of all reduces the catalyst activity, reflected by a negative exponent $n_{\mathrm{H}_{2} \mathrm{~S}}$ [18-20]. Secondly, the reaction orders for the other species may also be affected [18]. However, the number of investigations concerning the effect of $\mathrm{H}_{2} \mathrm{~S}$ on $\mathrm{FeCr}$-based catalysts is limited and more specifically, detailed reports of the effect of small amounts of $\mathrm{H}_{2} \mathrm{~S}$ (sweet shift) are few-while this is crucial for the development of pre-combustion CCS processes.

In the 1960s, Bohlbro published a series of papers on the kinetics of WGS over commercial FeCr-based WGS catalysts [18, 21-23], one of which specifically concerned the influence of $\mathrm{H}_{2} \mathrm{~S}$ on the rate equation [18]. WGS kinetics was measured with 75 and 2,000 ppmv of $\mathrm{H}_{2} \mathrm{~S}$ in the reactor feed. In the same paper, Bohlbro mentions that preliminary experiments indicate a significant effect on WGS kinetics is already obtained at $10-15$ ppmv $\mathrm{H}_{2} \mathrm{~S}$ in the feed gas. This effect, however, was not quantified. In the range of $30-100 \mathrm{ppmv}$ of $\mathrm{H}_{2} \mathrm{~S}$ at $380{ }^{\circ} \mathrm{C}$ and atmospheric pressure, Bohlbro [18] observed that the reaction rate decreased according to:

$R \propto p_{\mathrm{H}_{2} \mathrm{~S}}^{-0.35}$.

He also reported a marked change in reaction order for the other components with increasing concentration of $\mathrm{H}_{2} \mathrm{~S}$ at atmospheric pressure and $380{ }^{\circ} \mathrm{C}$. Xue et al. [19] tested a commercial FeCr-based catalyst between 300 and $350{ }^{\circ} \mathrm{C}$ in the presence of 50-1,000 ppmv $\mathrm{H}_{2} \mathrm{~S}$ and concluded that the catalyst activity decreased reversibly upon introduction of $\mathrm{H}_{2} \mathrm{~S}$. The reaction rate at $350{ }^{\circ} \mathrm{C}$ and atmospheric pressure was found to decrease with the concentration of $\mathrm{H}_{2} \mathrm{~S}$, according to:

$R \propto p_{\mathrm{H}_{2} \mathrm{~S}}^{-0.22}$.

At $1,000 \mathrm{ppmv}$ of $\mathrm{H}_{2} \mathrm{~S}$, approximately $50 \%$ of the activity without $\mathrm{H}_{2} \mathrm{~S}$ remained. More recently, Hla et al. [20] reported a study of the effect of 17-1,100 ppmv $\mathrm{H}_{2} \mathrm{~S}$ on the activity of a commercial high-temperature WGS catalyst (80-95\% $\mathrm{Fe}_{2} \mathrm{O}_{3}, 5-10 \% \mathrm{Cr}_{2} \mathrm{O}_{3}, 1-5 \% \mathrm{CuO}, 1-5 \%$ graphite). They found different exponents for the effect of $\mathrm{H}_{2} \mathrm{~S}$ in different concentration ranges from three different experiments at $450{ }^{\circ} \mathrm{C}$ and atmospheric pressure:

$$
\left\{\begin{array}{ll}
R \propto p_{\mathrm{H}_{2} \mathrm{~S}}^{-0.24 \pm 0.09} & \mathrm{H}_{2} \mathrm{~S}=17-70 \mathrm{ppmv} \\
R \propto p_{\mathrm{H}_{2} \mathrm{~S}}^{-0.54 \pm 0.04} & \mathrm{H}_{2} \mathrm{~S}=70-330 \mathrm{ppmv} \\
R \propto p_{\mathrm{H}_{2} \mathrm{~S}}^{-0.55 \pm 0.05} & \mathrm{H}_{2} \mathrm{~S}=120-1100 \mathrm{ppmv}
\end{array} .\right.
$$

In an earlier paper [24], Hla et al. had measured kinetics of the high-temperature WGS reaction over FeCr-based catalysts but their later study of the effect of $\mathrm{H}_{2} \mathrm{~S}$ [20] was done with a fixed syngas composition and consequently did not re-evaluate the exponents of species other than $\mathrm{H}_{2} \mathrm{~S}$. In conclusion, no full kinetic expression valid with 20 ppmv of $\mathrm{H}_{2} \mathrm{~S}$ has been published up till now. In the present study, the reaction kinetics for water-gas shift has been measured over a commercial FeCr-based catalyst at atmospheric pressure, at $375-475{ }^{\circ} \mathrm{C}$, with $11-35$ ppmv of $\mathrm{H}_{2} \mathrm{~S}$. It will be demonstrated that in this region the catalyst activity is negatively affected by $\mathrm{H}_{2} \mathrm{~S}$. A power rate law will be presented as fitted to our experimental data. Comparison with other kinetic expressions published in literature will show that a more elaborate kinetic model than a power rate law is better suited to fully capture kinetics over the entire transition regime from sulphur-free to high-sulphur.

\section{Experimental}

Experiments have been performed in a micro-reactor setup with automated flow control and gas analysis. Catalyst samples were tested in quartz reactor tubes of $8 \mathrm{~mm}$ internal diameter, containing in the centre an axially placed thermocouple tube of $3 \mathrm{~mm}$ external diameter. Gases were pure and supplied from bottles obtained from Air Liquide, the Netherlands, except for $\mathrm{H}_{2} \mathrm{~S}$, which was supplied as 200 ppmv $\mathrm{H}_{2} \mathrm{~S}$ in $\mathrm{N}_{2}$, obtained from Scott Specialty Gases, The Netherlands. Water was added by continuously saturating the dry gas with water at $90{ }^{\circ} \mathrm{C}$, and then condensing the surplus in a reflux cooler at the desired dew point between 57 and $64{ }^{\circ} \mathrm{C}$. Before entering the reactor, the gas feed was lead through a carbonyl trap at $250{ }^{\circ} \mathrm{C}$, decomposing potential metal carbonyls. The $\mathrm{H}_{2} \mathrm{~S} / \mathrm{N}_{2}$ mixture was added through a separate feed line directly into the reactor. Gas analysis $\left(\mathrm{CO}, \mathrm{CO}_{2}, \mathrm{CH}_{4}\right.$, and $\left.\mathrm{N}_{2}\right)$ was performed with a Perkin Elmer gas chromatograph equipped with a packed Poraplot/molsieve column (Alltech), TCD and FID. Samples of the $\mathrm{H}_{2} \mathrm{~S} / \mathrm{N}_{2}$ feed gas were measured for $\mathrm{H}_{2} \mathrm{~S}$ concentration offline using a Shimadzu GC 14B gas chromatograph with a Varian CP-Sil $5 \mathrm{CB} / \mathrm{MS}$ column and FPD. A commercial FeCr-based catalyst was used 
Table 1 Experimental conditions

\begin{tabular}{llllll}
\hline & $\begin{array}{l}\text { Low } \\
\text { extreme }\end{array}$ & Low & Centre & High & $\begin{array}{l}\text { High } \\
\text { extreme }\end{array}$ \\
\hline $\mathrm{T}\left({ }^{\circ} \mathrm{C}\right)$ & & 375 & 421 & 475 & \\
$\mathrm{P}(\mathrm{bar})$ & 0.2 & & & & \\
$\mathrm{CO}(\mathrm{mol} / \mathrm{mol})$ & & $4 \%$ & $6 \%$ & $11 \%$ & \\
$\mathrm{H}_{2} \mathrm{O}(\mathrm{mol} / \mathrm{mol})$ & $13 \%$ & $16 \%$ & $19 \%$ & \\
$\mathrm{CO}_{2}(\mathrm{~mol} / \mathrm{mol})$ & $6 \%$ & $10 \%$ & $14 \%$ & $19 \%$ & $37 \%$ \\
$\mathrm{H}_{2}(\mathrm{~mol} / \mathrm{mol})$ & $6 \%$ & $10 \%$ & $14 \%$ & $19 \%$ & $36 \%$ \\
$\mathrm{~N}_{2}(\mathrm{~mol} / \mathrm{mol})$ & Balance & & & & \\
$\mathrm{H}_{2} \mathrm{~S}(\mathrm{ppmv})$ & & 11 & 17 & & \\
$\mathrm{Total} \mathrm{flow}(\mathrm{mL} / \mathrm{min})$ & 100 & & & & \\
$\quad\left(25{ }^{\circ} \mathrm{C}, 1 \mathrm{~atm}\right)$ & & & & & \\
\hline
\end{tabular}

(85-90 wt $\% \mathrm{Fe}_{2} \mathrm{O}_{3}, 8-13$ wt $\% \mathrm{Cr}_{2} \mathrm{O}_{3}, 1-2 \mathrm{wt} \% \mathrm{CuO}$, commercially available pellets $6 \times 6 \mathrm{~mm})$. The catalyst was crushed and sieved to obtain a sieve fraction of $0.2-0.3 \mathrm{~mm}$ diameter. To prevent the occurrence of intra-particle temperature gradients at any but the lowest reaction temperature, the catalyst was ground to powder, mixed with 67-90 wt\% AKP-15 $\alpha$-alumina powder (Sumitomo Chemical, Japan), pressed to pellets, and then crushed and sieved to obtain particles in a range of $0.2-0.3 \mathrm{~mm}$ diameter. All sieve fractions were diluted further with $0.2-0.3 \mathrm{~mm}$ particles of pure $\alpha$-alumina from the same source, to such an extent that the catalyst bed contained $17-50 \mathrm{wt} \%$ of inert particles. Depending on the settings, 20-400 mg of catalyst was used.

The experimental conditions covered are shown in Table 1. Design of experiments was based on a full $2^{6}$ factorial design [25] plus centre points and added extremes for $\mathrm{CO}_{2}$ and $\mathrm{H}_{2}$. The centre point has been selected as the inverse or logarithmic average between the low and high values, following the mathematical form of Eq. 2. Low and high extremes for partial pressures of $\mathrm{CO}_{2}$ and $\mathrm{H}_{2}$ have been included into the design to accommodate the effect of selectively removing either of the reaction products, as would be the case in separation-enhanced WGS. All runs are measured in duplicate.

The $\mathrm{FeCr}$ catalyst is available as haematite/chromia $\left(\mathrm{Fe}_{2} \mathrm{O}_{3} / \mathrm{Cr}_{2} \mathrm{O}_{3}\right)$, possibly with traces of chromic oxide $\left(\mathrm{CrO}_{3}\right)$. The catalyst must therefore be reduced to its active form of magnetite/chromia $\left(\mathrm{Fe}_{3} \mathrm{O}_{4} / \mathrm{Cr}_{2} \mathrm{O}_{3}\right)$, while preventing over-reduction of iron oxide to $\mathrm{FeO}$ or even Fe [14]. Activation of the catalyst is done by heating from 120 to $300{ }^{\circ} \mathrm{C}\left(2^{\circ} \mathrm{C} / \mathrm{min}\right)$ and hold for $30 \mathrm{~min}$ at $300{ }^{\circ} \mathrm{C}$ in $1: 1$ hydrogen-steam mixture with balance nitrogen. It is known from literature that the main cause for catalyst deactivation is sintering: a decrease of the surface area and an increase of the mean pore size of the catalyst [26]. Sintering is enhanced by elevated temperature. In order for the data points to be measured on an aged catalyst, all kinetic measurements were therefore preceded by a double activity measurement $\quad\left(375-475-375-475-375{ }^{\circ} \mathrm{C}, \quad 0.6{ }^{\circ} \mathrm{C} / \mathrm{min}\right)$. Immediately following the kinetic measurements, the catalysts were again exposed to the same double activity measurement in order to confirm that no excessive deactivation had occurred during the kinetic settings. During the kinetic measurements methanation was not observed.

\section{Data Processing and Regression Analysis}

All measured kinetic data were validated using the following criteria:

1. Maximum $6 \%$ deviation of the carbon balance,

2. Measured $\mathrm{CO}$ conversion at least $5 \%$, since data at very low conversion are not sufficiently accurate in terms of the experimental errors,

3. Reactor outlet not at thermodynamic equilibrium $\left(\beta_{\mathrm{WGS}}<0.9\right)$, and

4. Intrinsic kinetics measurement according to the criteria formulated by Kapteijn and Moulijn [27].

A total of 176 data points fulfilled all criteria and have been used for fitting the kinetic expression.

The intrinsic kinetic Eq. 2 is numerically integrated over the reactor length in order to predict the conversion in an integral plug flow reactor. Since all criteria for intrinsic kinetics have been fulfilled, no mass or heat transfer effects have to be taken into account. Moreover, the reactor is operated isothermally. Therefore, an isothermal ideal plug flow reactor model suffices:

$\frac{\mathrm{d} p_{i}}{\mathrm{~d} \zeta}=\frac{W}{F} p_{\text {tot }} v_{i} R \quad i=1,2,3,4$

for $\mathrm{CO}, \mathrm{H}_{2} \mathrm{O}, \mathrm{CO}_{2}$, and $\mathrm{H}_{2}$

where $p_{i}$ is the partial pressure of component $i(\mathrm{kPa}), \zeta$ the dimensionless reactor length, $W$ the weight of catalyst $(\mathrm{kg})$, $F$ the total flow of reactants $(\mathrm{mol} / \mathrm{s}), p_{\text {tot }}$ the total pressure $(\mathrm{kPa}), v_{i}$ the stoichiometric coefficient of component $i$, and $R$ the intrinsic water-gas shift reaction rate $[\mathrm{mol} / \mathrm{kg} \mathrm{s}]$. The 
concentration of $\mathrm{H}_{2} \mathrm{~S}$ is assumed constant over the length of the reactor-a valid assumption because the catalyst has been exposed to $\mathrm{H}_{2} \mathrm{~S}$ for $10 \mathrm{~h}$ before kinetic measurements are done and no significant additional deactivation is observed during the kinetic measurements. Equations 2 and 7 are implemented in Matlab and integrated with a built-in solver for ordinary differential equations (ode45). The calculated CO conversion is fitted to the experimental data using nonlinear regression techniques. The Matlab Statistics Toolbox is used to perform the regression (nlinfit), to produce error estimates on predictions (nlpredci), and to produce error estimates on the estimated coefficients (nlparci). The Arrhenius type Eq. 2 is highly nonlinear and the error structure of the coefficient estimates can therefore be very complex. Optimal fit consequently requires all coefficients in the kinetic expression to be estimated simultaneously from the complete set of available experimental data [28]. In addition, the strong correlation between $k_{\infty}$ and $E_{\mathrm{a}}$ is suppressed by reparametrisation of the Arrhenius equation via introduction of a reference temperature $T_{\text {ref }}$ :

$$
\begin{aligned}
R= & k_{T_{\text {ref }}} \exp \left(-E_{\mathrm{a}} / R\left(\frac{1}{T}-\frac{1}{T_{\text {ref }}}\right)\right) \\
& \times p_{\mathrm{CO}}^{n_{\mathrm{CO}}} p_{\mathrm{H}_{2} \mathrm{O}}^{n_{\mathrm{H}_{2} \mathrm{O}}} p_{\mathrm{CO}_{2}}^{n_{\mathrm{CO}_{2}}} p_{\mathrm{H}_{2}}^{n_{\mathrm{H}_{2}}} p_{\mathrm{H}_{2} \mathrm{~S}}^{n_{\mathrm{H}_{2} \mathrm{~S}}}\left(1-\beta_{\mathrm{WGS}}\right) .
\end{aligned}
$$

In order to achieve maximum precision for the Arrhenius parameter estimates, the reference temperature must be properly selected as the reciprocal of the weighted average of the inverse temperature values in the experiments $\left(1 / T_{j}\right)$ [28]. It consequently differs from the centre point temperature reported in Table 1 .

The experimental error in the $\mathrm{CO}$ conversion from the GC analysis is larger when measuring low concentrations or concentration differences of species and therefore the variability of the measured data is not randomly distributed. Experiments done with a low amount of carbon monoxide and/or high conversion will have larger experimental errors, which will strongly affect regression. To compensate, a robust fitting technique has been applied: the error values have been corrected with a bisquare weighing function in order to limit the effect of outliers [29]. In addition, the random variability may well exert a large influence on the estimated factor effects. This is due to the limited number of repetitions and it is enhanced by the limited range of variation. In such a case, a data transformation may improve the fit [25, pp. 237-239]. Based on the mathematical structure of the rate equation, the natural logarithm of the CO conversion is used as the response for the regression.

\section{Results}

Estimates of the seven kinetic parameters and the corresponding 95\% confidence intervals are shown together with their $t$-statistics and $p$-values in Table 2. Regression is performed with an optimum reference temperature of 678 K. In Fig. 2, the quality of fit is represented by means of a parity plot and Fig. 3 shows the normal probability plot of the residuals.

The kinetic experiments and statistical analysis presented above have resulted in the following rate equation for the water-gas shift reaction 1, with pressures in $\mathrm{kPa}$ and temperature in $\mathrm{K}$ :

$$
\begin{aligned}
R= & (3.2 \pm 1.3) \cdot 10^{-6} \exp \left(-\frac{(112 \pm 2) \cdot 10^{3}}{R}\left(\frac{1}{T}-\frac{1}{678}\right)\right) \\
& \times p_{\mathrm{CO}}^{0.84 \pm 0.04} p_{\mathrm{H}_{2} \mathrm{O}}^{1.17 \pm 0.12} p_{\mathrm{CO}_{2}}^{-0.36 \pm 0.05} p_{\mathrm{H}_{2}}^{0.09 \pm 0.05} p_{\mathrm{H}_{2} \mathrm{~S}}^{-0.30 \pm 0.03} \\
& \times\left(1-\beta_{W G S}\right) \quad\left[\frac{\mathrm{mol}}{\mathrm{kg} \mathrm{s}}\right] .
\end{aligned}
$$

\section{Discussion}

The kinetics of WGS over a commercial catalyst could be described by power rate law in the range of measurement, including high and low extremes for $\mathrm{CO}_{2}$ and $\mathrm{H}_{2}$ partial pressures, as well as $\mathrm{H}_{2} \mathrm{~S}$ in the range of 11-35 ppmv. Even at this low concentration, $\mathrm{H}_{2} \mathrm{~S}$ clearly affects the reaction rate.
Table 2 Parameter estimates and optimum reference temperature

\begin{tabular}{lcllrr}
\hline Parameter & Estimate & $\begin{array}{l}\text { Estimated error } \\
(95 \% \text { conf. interval })\end{array}$ & Unit & $t$ Statistic & $p$-Value \\
\hline$k_{T_{\text {ref }}}$ & $3.2 \times 10^{-6}$ & $\pm 1.3 \times 10^{-6}$ & $\mathrm{~mol} / \mathrm{kg} \mathrm{s} \mathrm{kPa}^{1.44}$ & 5.00 & $<0.0001$ \\
$E_{\mathrm{a}}$ & 112 & \pm 2 & $\mathrm{~kJ} / \mathrm{mol}$ & 144.09 & $<0.0001$ \\
$n_{\mathrm{CO}}$ & 0.84 & \pm 0.04 & & 41.05 & $<0.0001$ \\
$n_{\mathrm{H}_{2} \mathrm{O}}$ & 1.17 & \pm 0.12 & & 19.95 & $<0.0001$ \\
$n_{\mathrm{CO}_{2}}$ & -0.36 & \pm 0.05 & -14.38 & $<0.0001$ \\
$n_{\mathrm{H}_{2}}$ & 0.09 & \pm 0.05 & & 3.64 & 0.0006 \\
$n_{\mathrm{H}_{2} \mathrm{~S}}$ & -0.30 & \pm 0.03 & -17.51 & $<0.0001$ \\
$T_{\text {ref }}$ & $678 \mathrm{~K}$ & & & \\
\hline
\end{tabular}




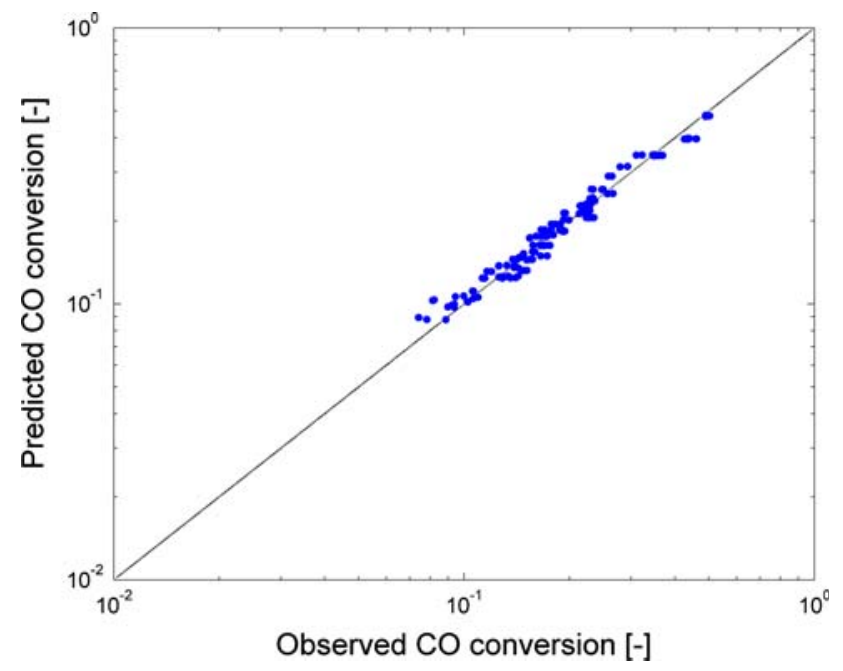

Fig. 2 Predicted versus observed CO conversion

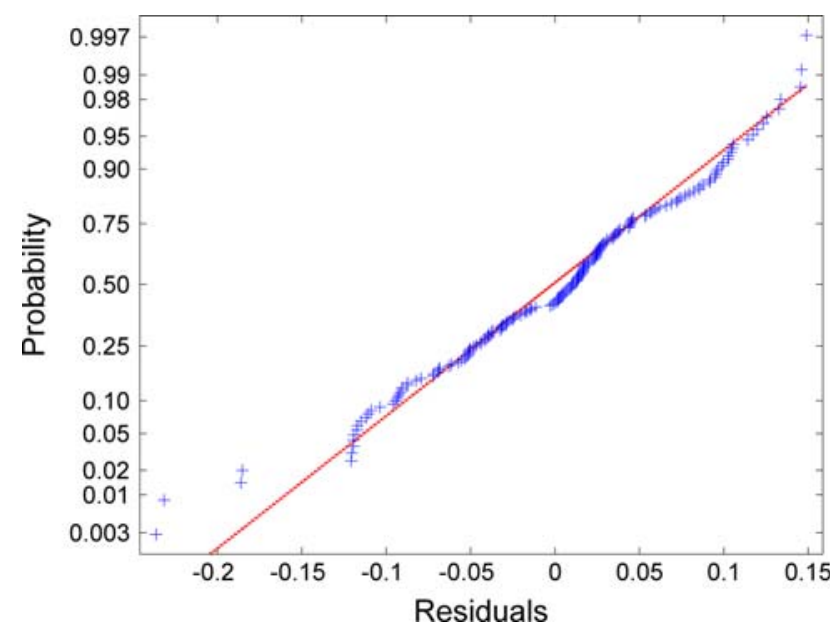

Fig. 3 Normal probability plot of residuals (residuals based on natural logarithm transformed response)

The activation energy is estimated with high accuracy (Table 2): clearly the covariance of the pre-exponential term with the activation energy is effectively counteracted by reparameterisation and choosing the appropriate reference temperature. Table 2 also shows that the pre-exponential term and the order for $\mathrm{H}_{2}$ have much lower $t$-statistics. Nevertheless, the $t$-statistics and corresponding $p$-values indicate that all estimates are significant at the 95\% confidence level. Finally, the estimate for the order in steam may have suffered from the fact that the setup did not allow a wide range of variation of the steam partial pressure (15-22 kPa).

The only work available in literature relating the reaction orders to the $\mathrm{H}_{2} \mathrm{~S}$ concentration is the kinetic studies by Bohlbro $[18,21]$. The activation energy and reaction orders of Bohlbro are compared with the present study in Table 3. The rate equation that is presently derived for 11-35 ppmv $\mathrm{H}_{2} \mathrm{~S}$ matches with the rate equations found by Bohlbro. The activation energy in the present study $(112 \mathrm{~kJ} / \mathrm{mol})$ corresponds to the activation energy of $115 \mathrm{~kJ} / \mathrm{mol}$ for clean measurements by Bohlbro. Similarly, Xue et al. [19] report an apparent activation energy of $117 \mathrm{~kJ} / \mathrm{mol}$ without $\mathrm{H}_{2} \mathrm{~S}$ and $105 \mathrm{~kJ} / \mathrm{mol}$ with $50 \mathrm{ppmv}$ of $\mathrm{H}_{2} \mathrm{~S}$.

Similarly, the reaction orders in the power rate law of the present study compare well with the reaction orders that were measured by Bohlbro. For $\mathrm{CO}$, the exponent of $0.84 \pm 0.04$ is within the range of values with 75 and $2,000 \mathrm{ppmv} \mathrm{H}_{2} \mathrm{~S}$. Bohlbro observed an increasing exponent for water upon the addition of $\mathrm{H}_{2} \mathrm{~S}$, followed by a decrease at higher $\mathrm{H}_{2} \mathrm{~S}$ concentrations. He advanced the hypothesis that this is caused by the competitive adsorption of $\mathrm{H}_{2} \mathrm{O}$ and $\mathrm{H}_{2} \mathrm{~S}$. The adsorption of $\mathrm{H}_{2} \mathrm{~S}$ may be suppressed to some extent by $\mathrm{H}_{2} \mathrm{O}$ in case the former is only present in small amounts (up to $75 \mathrm{ppmv}$ ). Upon the formation of bulk iron sulphide, expected at higher sulphur levels, the effect of $\mathrm{H}_{2} \mathrm{O}$ is then reduced again. Our high exponent for water is in line with these observations. In addition, the water exponent has probably been further increased by the fact that present experiments were performed at relatively low water partial pressures $(15-22 \mathrm{kPa})$ in comparison to the measurements by Bohlbro (7-79 $\mathrm{kPa})$. The decreasing exponent for $\mathrm{CO}_{2}$ may be explained as well by competitive adsorption of $\mathrm{CO}_{2}$ and $\mathrm{H}_{2} \mathrm{~S}$ on the same sites. Adsorption of $\mathrm{H}_{2} \mathrm{~S}$ would then lower the adsorbed amount of $\mathrm{CO}_{2}$ and thereby reduce the rate of reverse WGS. Consequently, an increase in the concentration of $\mathrm{H}_{2} \mathrm{~S}$ from 0 to $75 \mathrm{ppmv}$ leads to a continuous decrease in the exponent for $\mathrm{CO}_{2}$ that is already observed at $11-35 \mathrm{ppmv}$ of $\mathrm{H}_{2} \mathrm{~S}$. The reaction order for $\mathrm{H}_{2}$ in the present work was found to be +0.09 and this does not correspond with the findings of Bohbro ( 0 and -0.15 , respectively). Other published kinetic equations of clean WGS over FeCr-based catalysts either report no
Table 3 Activation energy and reaction orders as a function of the $\mathrm{H}_{2} \mathrm{~S}$ concentration, present study compared to values reported by Bohlbro [18, 21]

\begin{tabular}{llllllll}
\hline $\begin{array}{l}\mathrm{H}_{2} \mathrm{~S} \text { concentration } \\
\text { (ppmv) }\end{array}$ & $E_{\mathrm{a}}(\mathrm{kJ} / \mathrm{mol})$ & $n_{\mathrm{CO}}$ & $n_{\mathrm{H}_{2} \mathrm{O}}$ & $n_{\mathrm{CO}_{2}}$ & $n_{\mathrm{H}_{2}}$ & $n_{\mathrm{H}_{2} \mathrm{~S}}$ & Source \\
\hline 0 & 115 & 1.00 & 0.25 & -0.60 & 0 & & {$[21]$} \\
$11-35$ & 112 & 0.84 & 1.17 & -0.36 & 0.09 & -0.30 & Present study \\
75 & 93 & $0.75-0.80$ & 0.50 & -0.10 & -0.15 & -0.35 & {$[18]$} \\
2,000 & 95 & 0.85 & 0.40 & -0.10 & -0.10 & - & {$[18]$} \\
\hline
\end{tabular}


effect of hydrogen $\left(n_{\mathrm{H}_{2}}=0,[30,31]\right)$ or a small negative order $\left(-0.15 \leq n_{\mathrm{H}_{2}} \leq-0.04,[24,32]\right)$. While the value of $+0.09 \pm 0.05$ is close to zero and the $95 \%$ confidence interval relatively large, the effect is still significant as indicated by the $t$-value (Table 2). The positive reaction order for $\mathrm{H}_{2}$ may result from the fact that $\mathrm{H}_{2}$ aids to remove $\mathrm{H}_{2} \mathrm{~S}$ from the catalyst surface. In this respect, the interaction of $\mathrm{H}_{2} \mathrm{~S}$ with the catalyst should not be interpreted as the formation of iron sulphide that is expected at higher concentrations of $\mathrm{H}_{2} \mathrm{~S}$ [14]:

$\mathrm{Fe}_{3} \mathrm{O}_{4}+3 \mathrm{H}_{2} \mathrm{~S}+\mathrm{H}_{2} \leftrightarrow 3 \mathrm{FeS}+4 \mathrm{H}_{2} \mathrm{O}$.

Instead, $\mathrm{H}_{2} \mathrm{~S}$ adsorbs on the catalyst surface in the conditions applied [18, 33]. Accordingly, Bartholomew [33] presents relevant examples of dissociative adsorption of small amounts of $\mathrm{H}_{2} \mathrm{~S}$ on metal sites $(\bullet)$, forming surface sulphide:

$\mathrm{H}_{2} \mathrm{~S}+\bullet \leftrightarrow \mathrm{S} \bullet+\mathrm{H}_{2}$

The interaction between $\mathrm{H}_{2}$ and $\mathrm{H}_{2} \mathrm{~S}$ is indeed confirmed further by the regression results, indicating a negative covariance of -0.0315 (on a scale of -1 to 1 ) between $n_{\mathrm{H}_{2}}$ and $n_{\mathrm{H}_{2} \mathrm{~S}}$. Finally, in the exponent for $\mathrm{H}_{2} \mathrm{~S}$ there is a slight difference with the values reported by Bohlbro, but this is not statistically significant: Bohlbro found an exponent of -0.35 for the range of $30-100 \mathrm{ppm}$ while the present work leads to an exponent of $-0.30 \pm 0.03$ in the range of 11-35 ppm. At the 95\% confidence level the latter value also corresponds to the exponent of $-0.24 \pm 0.09$ in the range of 17-70 ppmv $\mathrm{H}_{2} \mathrm{~S}$ as recently reported by Hla et al. [20]. Xue et al. [19] found an exponent for $\mathrm{H}_{2} \mathrm{~S}$ of -0.22 with $50-1,000$ ppmv of $\mathrm{H}_{2} \mathrm{~S}$, but this value is more difficult to interpret as information on the confidence interval is lacking.

The experimental results and the discussion above indicate that the exponents for all species involved in the reaction change with $\mathrm{H}_{2} \mathrm{~S}$ rising from 0 to $75 \mathrm{ppmv}$. Bohlbro observed this difference in reaction orders when going from 0 to 75 ppmv $\mathrm{H}_{2} \mathrm{~S}$-whereas a further increase to 2,000 ppmv changed relatively little. These observations are further supported by the present study at $11-35 \mathrm{ppmv}$ $\mathrm{H}_{2} \mathrm{~S}$. Comparing the reaction orders determined in the present study with those reported in literature supports Bohlbro's observation that a transition takes place in the observed rate equation between 0 and $75 \mathrm{ppmv}$ of $\mathrm{H}_{2} \mathrm{~S}$. While the reaction kinetics at each of the $\mathrm{H}_{2} \mathrm{~S}$ concentration levels could be described satisfactorily with a power rate law, the reaction orders change with increasing $\mathrm{H}_{2} \mathrm{~S}$ concentration. Apparently, the power law equation does not accommodate all relevant underlying phenomena. In contrast, Langmuir-Hinshelwood kinetics for example includes surface adsorption effects and depends in shape upon the rate determining elementary steps $[14,31,32,34,35]$. Over a limited range of operating conditions, the distribution of chemisorbed reaction intermediates may remain constant and the observed reaction rate may be approximated by power law kinetics. From the fact that a power rate law cannot satisfactorily describe the entire range of clean to sour water-gas shift kinetics, it is deduced that a significant change occurs in the distribution of chemisorbed reaction intermediates. In conclusion, a more elaborate kinetic model, such as a Langmuir-Hinshelwood model accounting for changes in the distribution of surface species, would be better suited to describe the kinetics over the whole range of $\mathrm{H}_{2} \mathrm{~S}$ concentrations from 0 to $2,000 \mathrm{ppmv}$, specifically in the intermediate range from 0 to $75 \mathrm{ppmv}$.

\section{Conclusion}

Water-gas shift kinetics has been measured over a commercial FeCr-based catalyst. Nonlinear regression was carried out based on 176 experimental data points, resulting in the following rate equation:

$$
\begin{aligned}
R & =(3.2 \pm 1.3) \cdot 10^{-6} \exp \left(-\frac{(112 \pm 2) \cdot 10^{3}}{R}\left(\frac{1}{T}-\frac{1}{678}\right)\right) \\
& \times p_{\mathrm{CO}}^{0.84 \pm 0.04} p_{\mathrm{H}_{2} \mathrm{O} \pm 0.12}^{1.17} p_{\mathrm{CO}_{2}}^{-0.36 \pm 0.05} p_{\mathrm{H}_{2}}^{0.09 \pm 0.05} p_{\mathrm{H}_{2} \mathrm{~S}}^{-0.30 \pm 0.03} \\
& \times\left(1-\beta_{\mathrm{WGS}}\right) \quad\left[\frac{\mathrm{mol}}{\mathrm{kg} \mathrm{s}}\right] .
\end{aligned}
$$

The kinetics of WGS over a commercial catalyst could thus be well described by a power rate law in the presented operating range, including high and low extremes for $\mathrm{CO}_{2}$ and $\mathrm{H}_{2}$ content as well as 11-35 ppmv of $\mathrm{H}_{2} \mathrm{~S}$. Hence, the presented power rate law is valid in conditions that are specific for separation-enhanced water-gas shift in precombustion $\mathrm{CO}_{2}$ capture.

Even at this low concentration, $\mathrm{H}_{2} \mathrm{~S}$ significantly affects the reaction rate. The resulting equation compares well with literature data, indicating a transition in the observed kinetics between 0 and $75 \mathrm{ppmv} \mathrm{H}_{2} \mathrm{~S}$. At a concentration of 11-35 ppmv, $\mathrm{H}_{2} \mathrm{~S}$ does not form metal sulphides, but adsorbs on the surface instead. Accordingly, the kinetics of WGS over a FeCr-based catalyst in the entire range of 0-75 ppmv $\mathrm{H}_{2} \mathrm{~S}$ can only be captured satisfactorily by a more elaborate kinetic model.

Acknowledgements This work is part of the Global Climate and Energy Project (GCEP, http://gcep.stanford.edu/). The authors gratefully acknowledge the GCEP sponsors for financial support.

\section{References}

1. Pehnt M, Henkel J (2009) Int J Greenh Gas Control 3(1):49

2. Odeh NA, Cockerill TT (2008) Energy Policy 36(1):367 
3. IPCC (2005) In: MetzB, Davidson O, de Coninck H, Loos M, Meyer L (eds) Special report on carbon dioxide capture and storage. Prepared by Working Group III of the Intergovernmental Panel on climate change. Cambridge University Press, Cambridge/New York

4. Jansen D, Haije WG, Dijkstra JW, Brink Rvd (2008) GCEP 2008 technical report, chap 2.4.2. Stanford University

5. Bredesen R, Jordal K, Bolland O (2004) Chem Eng Process 43(9): 1129

6. Flytzani-Stephanopoulos M, Qi X, Kronewitter S (2004) Watergas shift with integrated hydrogen separation process. Tufts University, Medford, MA

7. Bracht M, Alderliesten PT, Kloster R, Pruschek R, Haupt G, Xue E, Ross JRH, Koukou MK, Papayannakos N (1997) Energy Convers Manage 38(Suppl 1):S159

8. Carbo MC, Jansen D, Haije WG, Verkooijen AHM (2006) Advanced membrane reactors for fuel decarbonisation in IGCC: $\mathrm{H}_{2}$ or $\mathrm{CO}_{2}$ separation? Presented at the fifth annual conference on carbon capture and sequestration, Alexandria, VA, 2006

9. Allam R, Chiang R, Hufton JR, Weist E, White V, Middleton P (2004) Power generation with reduced $\mathrm{CO}_{2}$ emissions via the sorption enhanced water gas shift process. Presented at the third annual conference on carbon capture and sequestration, Alexandria, VA, 2004

10. van Selow ER, Cobden PD, Van den Brink RW, Hufton JR, Wright A (2009) Energy Procedia 1(1):689

11. Maurstad O (2005) An overview of coal based Integrated Gasification Combined Cycle (IGCC) Technology. Massachusetts Institute of Technology, Cambridge, MA

12. Korens N, Simbeck DR, Wilhelm DJ (2002) Process screening analysis of alternative gas treating and sulfur removal for gasification. U.S. Department of Energy-National Energy Technology Laboratory, Pittsburgh, PA

13. Kohl AL, Nielsen RB (1997) Gas purification. Gulf Professional Publishing, Boston, MA

14. Lloyd L, Ridler DE, Twigg MV (1989) In: Twigg MV (ed) Catalyst handbook, chap 6. Wolfe, London
15. Newsome DS (1980) Catal Rev Sci Eng 21(2):275

16. Kikuchi E, Uemiya S, Sato N, Inoue H, Ando H, Matsuda T (1989) Chem Lett 18(3):489

17. Uemiya S, Sato N, Ando H, Kikuchi E (1991) Ind Eng Chem Res 30(3):585

18. Bohlbro H (1963) Acta Chem Scand 17(4):1001

19. Xue E, O'Keeffe M, Ross JRH (1996) Catal Today 30(1-3):107

20. Hla SS, Duffy GJ, Morpeth LD, Cousins A, Roberts DG, Edwards JH (2009) Catal Commun 10(6):967

21. Bohlbro H (1961) Acta Chem Scand 15(3):502

22. Bohlbro H (1962) Acta Chem Scand 16(2):431

23. Bohlbro H (1964) J Catal 3(3):207

24. Hla SS, Park D, Duffy GJ, Edwards JH, Roberts DG, Ilyushechkin A, Morpeth LD, Nguyen T (2009) Chem Eng J 146 (1): 148

25. Montgomery DC (2005) Design and analysis of experiments. Wiley, New York

26. Keiski RL, Salmi T (1992) Appl Catal A 87(2):185

27. Kapteijn F, Moulijn JA (1997) In: Ertl G, Knötzinger H, Weitkamp J (eds) Handbook of heterogeneous catalysis, chap 9.1. Wiley-VCH, Weinheim

28. Schwaab M, Pinto JC (2007) Chem Eng Sci 62(10):2750

29. Matlab Statistics Toolbox 7 (2009) In: User's guide. The MathWorks, Natick, MA

30. Bohlbro H (1961) Acta Chem Scand 15:502

31. Keiski RL, Salmi T, Niemisto P, Ainassaari J, Pohjola VJ (1996) Appl Catal A 137(2):349

32. Podolski WF, Kim YG (1974) Ind Eng Chem Process Des Dev 13(4):415

33. Bartholomew CH, Agrawal PK, Katzer JR (1982) Adv Catal $31: 135$

34. Chorkendorff I, Niemantsverdriet JW (2003) Concepts of modern catalysis and kinetics. Wiley-VCH, Weinheim

35. Kumar P, Akpan E, Ibrahim H, Aboudheir A, Idem R (2008) Ind Eng Chem Res 47(12):4086 